$\mathrm{I}$ n September 1998 Cape Town hosted the Annual General Meeting and International Congress of the International Bobath Instructors Association, an association which promotes the evaluation and treatment of adults with hemiplegia according to the neurodevelopmental or Bobath concept. Sackley and Lincoln (1996), in a survey of current practice in the treatment of stroke patients which was conducted in Britain found that $80 \%$ of the therapists who treated these patients used the Bobath approach. However, they found that these same therapists rarely used standardised outcome measures and were reluctant to provide a reasoned account of the theoretical basis for their choice of treatment. This view is supported by Lennon (1996) in a critical review of the theoretical assumptions which guide physiotherapy practice in stroke rehabilitation. The Cape Town congress, however, made it very clear that the current theoretical assumptions underlying NDT (or Bobath) philosophy have developed considerably during the last decade, both during the Bobaths' lifetime and since. Current theoretical assumptions cover not only neurophysiological systems, but also biomechanical, motor control, motor learning, cognitive, behavioural and emotional aspects

Contrary to the claims of proponents of motor retraining to the exclusion of other approaches, these updated theoretical assumptions were adopted some years ago and continue to develop (Bly, 1991). Is it reluctance to publish which has prevented this from becoming common knowledge?

Practitioners in the neurodevelopmental approach to the treatment of patients with disorders of the central nervous system have also been criticised for their failure to publish outcome studies. As in other fields of physiotherapy, many studies have been published on measurement instruments but very few on the outcome of treatment. One of the reasons cited for this failure is the diffi- culty in measuring quality of movement. Another is the difficulty in matching experimental and control groups as well as the ethical dilemma of withholding treatment from a control group. The need for evidence-based practice cannot, however, be ignored. We can only justify our approach to treatment if we can produce outcome studies to support our theoretical assumptions. However, outcome studies must be well-designed, intervention must be relevant and outcome measures must be valid. A recent study on task-orientated activity, published by proponents of the motor learning approach, failed sadly in these respects (Dean and Shepherd, 1997).

We should acknowledge the mistakes of the past. The European Consensus Meeting of Stroke (1995) came to the conclusion that there was little evidence that rehabilitation beyond six months after stroke could improve motor or perceptual deficits. Watson (1997) has, however, cited several studies giving evidence for late-stage motor recovery in adults with severe traumatic brain injury. Other studies of severely disabled patients also suggest that recovery may take place more slowly and for longer in this group than in less severely disabled subjects. Equally important, Lindmark and Hamrin (1996) have shown a significant deterioration in stroke patients' ability to perform everyday activities one and five years post-stroke. Most of us can cite patients whom we started to treat long after six months post-insult, and in whom good results were achieved, but our failure to employ sound research methodology resulted in our inability to publish our findings.

A much neglected area in stroke rehabilitation is the upper limb. The majority of outcome studies have concentrated on achieving independent gait. A recent article published by Hale and Eales (1998) in this country noted the recovery of walking function in a group of patients from an under-serviced community, despite minimal intervention. However, independent walking by no means guarantees independence in activities of daily living, and the discussion article in this issue of the Journal gives insight into the complexities and limitations of regaining satisfactory upper limb function.

The articles published in this issue represent a selection of the papers presented at the IBITAH congress and demonstrate the balanced attention which therapists are starting to give to research into stroke and the outcomes of treatment. In addition to the discussion article they comprise the study of a measurement instrument, a randomised balanced study on the effects of footwear on gait and, finally, a study on the problems experienced by Black Stroke patients in Soweto, South Africa. $\square$

\section{SHEENA H. IRWIN-CARRUTHERS}

\section{REFERENCES}

Bly L (1991) A historical and current view of the basis of NDT, Pediatric Physical Therapy 3: $131-135$

Dean CM, Shepherd RB (1997) Task-related training improves performance of seated reaching tasks after stroke - a randomised controlled trial, Stroke 28: 722-728

Hale LA, Eales CJ (1998) Recovery of walking function in stroke patients after minimal rehabilitation, Physiotherapy Research International, 3: 194-205.

Lennon S (1996) The Bobath concept: a critical review of the theoretical assumptions that guide physiotherapy practice in stroke rehabilitation, Physical Therapy Reviews 1: 35-45.

Lindmark B, Hamrin R (1996) Stroke patients' abilityto perform everyday activities $I$ and 5 years post-stroke, Physiotherapy Theory and Practice 12: 97-101.

Sackley CM, Lincoln NB (1996) Physiotherapy treatment for stroke patients: a survey of current practice, Physiotherapy Theory and Practice 12: 87-96.

Watson MJ (1997) Evidence for "significant" late-stage motor recovery in patients with severe brain injury: a literature review with relevance for neurological physiotherapy, Physical Therapy Reviews 2: 93-106. 